Revue d'histoire de l'Amérique française

REVUE D.HISTOIRE DE L'AMÉRIQUE FRANÇAISE

\title{
L'objectivité absolue est-elle accessible à l'historien ? \\ Romano Guardini, Les fins dernières (Paris, 1950), 111-113
}

Volume 5, numéro 3, décembre 1951

URI : https://id.erudit.org/iderudit/037790ar

DOI : https://doi.org/10.7202/037790ar

Aller au sommaire du numéro

Éditeur(s)

Institut d'histoire de l'Amérique française

ISSN

0035-2357 (imprimé)

1492-1383 (numérique)

Découvrir la revue

Citer ce document

(1951). L'objectivité absolue est-elle accessible à l'historien ? / Romano

Guardini, Les fins dernières (Paris, 1950), 111-113. Revue d'histoire de l'Amérique

française, 5(3), 461-461. https://doi.org/10.7202/037790ar d'utilisation que vous pouvez consulter en ligne.

https://apropos.erudit.org/fr/usagers/politique-dutilisation/ 


\section{L'OBJECTIVITÉ ABSOLUE EST-ELLE ACCESSIBLE $\bar{A}$ L'HISTORIEN?}

Avant toute autre chose, l'historicité évoque ce que l'existence a d'opaque et de scellé. D'abord parce que le réseau des causes et des effets ne peut être l'objet ni d'une vision d'ensemble ni d'un sondage en profondeur. D'innombrables conditions préalables convergent en toute action. Pour sa part, l'action passée continue à opérer par des voies entrelacées et souterraines, dont bien peu d'entre elles peurent être établies avec certitude. Chaque épisode est tissé de beaucoup d'autres, oui, finalement de tous les autres. Comprendre vraiment un événement n'est possible qu'en le situant dans son contexte; or celui-ci s'étend à l'infini et échappe à une vue d'ensemble. On ne peut pas davantage le poursuivre jusqu'en son dernier retranchement, car au delà de chaque couche s'en trouve toujours une autre, et puisqu'un événement ne peut être entièrement intelligible qu'en le prenant jusqu'en ses racines, la majeure partie de lui-même échappe à nos prises.

A cela s'ajoute autre chose. Ce qui est vivant tend à s'exprimer. Toujours à nouveau, l'intériorité se projette dans l'apparence, l'être caché se manifeste dans ce qui est perceptible aux sens. Mais ce n'est là qu'une des faces de la relation - ce même vivant s'enfouit aussi en lui-même, recouvre l'essentiel. Dans la plante et chez l'animal, cette alternance d'expressivité et de recèlement est guidée par la nature elle-même et se tient en un équilibre significatif; chez l'homme, s'y ajoute la volonté consciente, et cette volonté est remplie de contradiction. Souvent l'interne demeure caché, là où il eût fallu qu'il soit manifesté; souvent l'apparence n'exprime pas le sens, bien que la situation le réclame. L'intention que l'on a en vue se voile et tout devient problématique. Les circonstances dans lesquelles l'expression a lieu en renversent parfois l'entière signification et la rendent trompeuse. L'homme peut en arriver à se cacher à lui-même son for interne et à se donner le change sur ses propres intentions. Ainsi se crée un état d'imperméabilité fermé au regard; état même d'ambiguitté et d'erreur où l'on s'egare et auquel le jugement ne peut se fier. Tout cela donne à l'histoire un caractère d'opacité, d'inintelligibilité, plus fort même, de duplicité et de perfidie.

(Romano Guardini, Les fins dernières (Paris, 1950), 111-113).

En vente:

Les Oeuvres de Champlain (éd. Laverdière) en 2 volumes. Très belle reliure.

Relations des Jésuites (éd. de la Librairie Côté, Québec, 1858) en 3 volumes reliés.

S'adresser, pour renseignements, à 261, a venue Bloomfield, Outremont, secrétariat de la Revue d'Histoire de l'Amérique française. 